\title{
Alien Hand Phenomena: A Review with the Addition of Six Personal Cases
}

\author{
C.M. Fisher
}

\begin{abstract}
This is a comprehensive literature review of the motor abnormalities that have come to be included under the designation of Alien Hand Phenomena (AHP). Some of the disorders are dyspractic in nature - intermanual conflict, mirror movements, interference etc., while others - groping, grasping with inability to release, utilization etc. are frontal lobe reflexes. AHP are mainly associated with two pathological processes: 1) Infarction or hemorrhage in the territory of the anterior cerebral arteries; and 2) Corticobasal degeneration. Included in the review is a description of AHPin six personal cases of corticobasal degeneration. The summary includes a short discussion of the possible anatomy of 'free will'based on AHP.
\end{abstract}

RÉSUMÉ: Le phénomène de l'activité motrice involontaire ou "alien hand syndrome": revue de la littérature et données sur six cas personnels. Il s'agit d'une revue exhaustive de la littérature sur les anomalies motrices qui sont maintenant désignées sous le nom de "alien hand syndrome" (AHS). Certaines des affections sont d'une nature dyspraxique - conflits intermanuels, mouvements en miroir, interférence etc., alors que d'autres - tâtonnement, préhension avec incapacité de relâcher, utilisation etc. sont des réflexes du lobe frontal. L'AHS est associé principalement à deux processus pathologiques: 1) L'infarctus ou l'hémorragie dans le territoire des artères cérébrales antérieures et 2) la dégénérescence corticobasale. Une description de six cas personnels d'AHS dus à une dégénérescence corticobasale est jointe à la revue. Le sommaire comprend une courte discussion du fondement anatomique probable de l'action volontaire sur la base du AHS.

Can. J. Neurol. Sci. 2000; 27: 192-203

The alien hand sign, also referred to as the alien hand syndrome, the alien-limb syndrome and the alien-limb phenomenon, includes a series of motor disorders involving one or both arms (or legs), some dyspractic, others consistent with complex 'reflex' activity. This class of movement disorders has been recognized for a century but has drawn attention only relatively recently. The manifestations are numerous and varied and, like all motor disorders, difficult to put into words. Nevertheless their recognition, classification and analysis depend on verbal description. The aim of the present review is to provide enough detail that readers not versed in the field can readily become acquainted with the subject. The emphasis is on the clinical description of the abnormal movements. The requirement that sufficient detail be provided, outweighs the need for brevity. The broad clinical picture and the neuropsychological assessment of the dyspractic state are omitted. Remarks are added when events seem to contribute to knowledge of the dyspractic process.

Alien hand phenomena (AHP) have been associated mainly with two unrelated groups of cases: Group I: lesions of the corpus callosum and/or the anteromedial frontal cortex including the supplementary motor area (unilateral or bilateral); and Group II: corticobasal degeneration (CBD).

Group I: The pathological processes include: surgical section of the corpus callosum (for epileptic seizures), infarction in the territory of an anterior cerebral artery (ACA), ruptured saccular aneurysm of the ACA, often with surgical clipping, callosal tumor, Marchiafava-Bignami disease, angioma of the corpus callosum, bullet wound etc. These conditions identify the theater of action, namely the corpus callosum and the ACAterritory. The clinical picture is generally interpreted in terms of interhemispheric disconnection, with or without damage to one supplementary motor area or both. The processes are mostly acute, followed by improvement.

Group II: Corticobasal degeneration, a rare condition is being increasingly recognized. The anatomical substrate is the parietal and posterior frontal cortex bilaterally. The process is 'degenerative', chronic, progressive and irreversible.

The term "alien hand" originally had quite a restricted connotation. Its scope has been expanded to apply, not always in

From the Neurology Service of the Massachusetts General Hospital, Boston MA02114 USA.

Received February 18, 2000. Accepted infinalform May 10, 2000.

Reprint requests to: C. Miller Fisher, Massachusetts General Hospital, Harvard Medical School, Neurology Service, Fruit Street, Boston 02114, MA, USA 
consistent fashion, to several types of abnormal behavior. The following is a compilation of clinical performances that at present are included under the rubric of alien hand.

1. Failure to identify an upper limb as one's own on palpating it behind the back or with the eyes closed. This was the original definition.

2. Movements of a limb which the patient regards as foreign, involuntary (unwilled), strange, uncooperative or interfering, the limb seeming to act on its own, outside the patient's control. Included in this category are intermanual conflict, mirror movements, and enabling synkinesis. The last refers to the inability of an arm to act on its own, but able to act in unison with the other arm. All of these abnormal movements are a manifestation of dyspraxia in that they are substitutions for, or additions to, an intended or willed act whose neural circuitry has been damaged. The misactions are not spontaneous, arising de novo, but are anomalous imitations, resemblances or additions to the intended act. While the overall pattern may fall within the category of alien hand, the details of a performance are unending. Although the movements are unwilled, patients feel or sense the movements and are always aware that the wayward limbs are theirs. Rarely do patients deny ownership of a limb.

3. Stereotyped 'reflex' motor activity associated with frontal lobe lesions: reaching out, groping, grasping, grasping with inability to release (tonic grasping, tonic innervation), utilization behavior, tactile and visual oral reactions.

4. Other: withdrawal of a limb, flinging movements of opticosensory ataxia.

These abnormal behaviors cannot be attributed to failure to understand, inattention, uncooperativeness, amnesia, delusions, dementia etc. On the contrary, patients are usually alert, conversant, cooperative, interested and aware of the movements requested. Their reactions vary from torment, to frustration, to amusement. Identifiable neurological movement disorders like dystonia, ataxia, choreoathetosis, tics, and catalepsy are not a factor.

The plan is to describe the Group I patients first (callosotomy, ACA infarction etc.), following which the CBD cases will be presented separately. A small category of unusual types follows. Finally personal observations in CBD will be described.

The cases are generally presented chronologically in order that the evolution of the concept can be appreciated. The pathological diagnosis is placed at the beginning of each presentation.

\section{Group I - Callosotomy, ACA infarction, etc.}

In 1945, Akelaitis ${ }^{1}$ described unusual, unintentional behavior in two patients who had undergone surgical section of the corpus callosum (callosotomy) in the treatment of intractable epileptic seizures. There was an apparent conflict between the intended act and the act actually performed, a behavior he termed 'diagonistic dyspraxia'. Akelaitis, in a series of papers covering 30 cases, reported the general absence of any abnormal neurological sequelae of callosotomy and ascribed the unusual activities in his two patients to psychiatric factors. It shortly became evident that detecting signs of interhemispheric disconnection required special neurological testing not used by Akelaitis, and his erroneous conclusion was explained. The five main signs of interhemispheric disconnection are: 1) ideomotor dyspraxia (usually of the left hand); 2) tactile anomia; 3) impaired intermanual sensory transfer; 4) impaired reading in the left visual field; and 5) suppression of left ear input on dichotic listening.

Akelaitis ${ }^{1}$ reported that in his first patient, in tasks requiring bimanual activity, the left hand would frequently perform oppositely to what she, the patient, desired to do with the right hand. For example, she would be putting on her clothes with the right hand and pulling them off with the left hand. Or she opened a door or drawer with the right hand and simultaneously pushed it shut with the left hand. Often these activities occurred simultaneously but frequently they would alternate. She would put a stocking on with her right hand and then pull it off with her left hand, repeating the performance several times. She would dry the clean dishes and then put them back into the pan to be washed again, realizing during the act or shortly thereafter that it was an absurd action. When she wanted to quench her thirst she would fill a glass with water and then pour it out, realizing all the time that she was thirsty and wanted a drink. If she concentrated on 'thinking of drinking' she could finish the act of drinking satisfactorily. She might want to get up from a sitting position and would succeed in raising herself partly, only to have a sudden desire to sit down again which she would proceed to do. While standing, she might want to go forward to get something but would remain motionless, crying out 'I want to walk forward but something makes me go backward.' Frequently she would start toward a destination such as a window in order to open it but eventually would find herself going toward the door in the opposite direction. Apparently she did not exhibit a grasp reflex or forced grasping in either hand. This behavior began six weeks postoperatively and lasted three weeks. The patient was probably not examined neurologically during this period. A second corpus callosum section was performed and was not followed by recurrence of diagonistic dyspraxia.

In the second case, a 27-year-old left-handed man with intractable seizures underwent total corpus callosum section. The episodes of dyspraxia began about one month later and were characterized by repeatedly performing an act and reversing it, or by a temporary inability to continue with an act. With his left hand he picked up a loaf of bread at a store only to replace it, repeating this several times to the annoyance of the clerk. When proceeding to the cellar to fetch coal, he stopped at the threshold and stepped back and forth several times unable to continue on. He put bread into the toaster only to withdraw it, doing this repeatedly for five minutes. On another occasion, he stopped at the foot of the front stairs unable to proceed. He would repeatedly put on a garment and take it off again. At times he was temporarily unable to take a garment from a closet. He found that on these occasions he had especially to 'will'himself to carry out the acts. He never showed these behaviors while eating, drinking, smoking or playing cards. He was also subject to attacks in which he was unable 'to will'his right hand to act, for example, unable to withdraw it from his pocket. While carrying an object in his right hand he had a feeling he was dropping it. These episodes continued sporadically for three years. The term 'diagonistic'(double agonist) is both etymologically correct and descriptive. The suffix 'ic'is somewhat unwieldy and also led to misreading the term as 'diagnostic'. 
In 1962, Gazzaniga, Bogen and Sperry ${ }^{2}$ in an early case of surgical callosotomy for epilepsy, observed that the patient, on verbal command, could not place his left hand behind his head or use it to point to something, whereas these acts could be carried out when the subject was directed to use both hands in the act. Frequently when his left hand had been fumbling ineffectively at some task, the patient would become exasperated and reach across with the right hand to grab the left hand and place in the proper position. The patient's wife observed that he would pick up the evening paper with the right hand but put it down abruptly with the left hand and then have to pick it up again with the right hand. Similar opposite movements were observed occasionally in the course of dressing and undressing on a scale sufficient to be distinctly bothersome. 'It was as if the control of the left hand were strongly centered in the minor hemisphere at such times and hence isolated from the main intent and prevailing directorship of the dominant hemisphere.'

Fisher $^{3}$ (ruptured ACA aneurysm) described a patient who complained that her hands 'bother me and exasperate me.' Whenever she did anything with the right hand the left hand 'butted in' and wanted to take over. She called her left hand 'my buttinski'. She could not touch her left ear with the left hand. On the command, "Touch your left ear with your right hand", as the right hand approached the ear, the left hand flew up and touched the ear first. 'The left hand tries to get into the act.' When suddenly asked without warning to snap her right fingers as quickly as possible, the left fingers snapped just before the right fingers. On reaching for a glass of water, the left hand automatically came over and took hold of the glass along with the right hand. When asked to mime lighting a cigarette, the patient made the correct movements of striking a match with the right hand but the left hand made a similar motion. As the right hand was brought towards the face, the left hand arrived ahead of it and came close to the mouth. When requested to tap with a pencil whenever she heard the number three in a series of numbers being read aloud, the right hand was performing satifactorily when the left hand took hold of the pencil and tapped indiscriminately.

The patient said that her left hand wanted 'to hold on to things'. When dealing cards her fingers clung to the cards. On putting a letter into an envelope, the left fingers clung to the writing paper and pulled it out of the envelope. In winding a clock, the left hand could not be released in order to wind. There was no grasp reflex on the left side on the usual maneuvers. The abnormal activities of the left arm were characterized as 'mirror movements'. The patient's choice of descriptive terms was not suggested by her attendants.

Schaltenbrand ${ }^{4}$ (tumor of the corpus callosum) - When the patient's hair was placed down over the left side of her face, her left hand would brush it back in place. But this act could not be done on command. A simple tactile, proprioceptive, elementary act succeeded when an ideationally driven process failed.

Sperry et $\mathrm{al}^{5}$ (callosotomy) - The patient was seen pulling down his pants with one hand and pulling them up with the other hand. The offending hand was not identified.

Brion and Jedynak ${ }^{6}$ (three cases of tumor of the corpus callosum, one angioma) - The authors introduced the 'alien hand sign' (le signe de la main étrangère) to draw attention to their newly recognized clinical sign of the corpus callosum disconnection syndrome. The patient failed to recognize as his own one of his hands, usually the left, when the hands felt each other behind the back (or in front with the eyes closed). From this definition the term was later broadened to apply when the patient feels that the behavior of his hand or limb is strange, foreign, disconcerting or uncooperative and is involuntary or unwilled. $^{7}$ No case of alien hand, as defined by Brion and Jedynak, has been reported since their original description.

Wilson et $\mathrm{al}^{8}$ (post-commissurotomy) - For a week or two after operation, one patient was aware of competition between his right and left hands, 'they want to do opposite things'. Other patients had the 'stranger's hand sign'in which they felt the left hand no longer belonged to them.

Joynt $^{9}$ (right ACA infarction) - When the patient wrote out checks with his own right hand, the left hand would gently rise up, grasp the right hand and move it aside.

Barbizet et $\mathrm{al}^{10}$ (Marchiafava-Bignami disease) - The patient displayed a rather complete picture of interhemispheric disconnection; in particular, bimanual cooperation was lacking. On simultaneously tapping the two hands rhythmically on a table top, the left one promptly came to a halt. In a task of wrapping two books in a paper, the left hand withdrew one of the books while the right hand replaced it. In purchasing an article, the right hand took the article while the left hand reclaimed the payment. Also in steering a car, the left hand performed well while the right hand interfered. During eating the left hand seemed to be engaged in untoward movements. These bimanual disorders could not be attributed to ideational apraxia since each hand by itself could perform satisfactorily. The authors thought that this bimanual asynergia represented the diagonistic dyspraxia of Akelaitis.

Bogen, ${ }^{7}$ in his comprehensive chapter on the callosal syndrome following surgical section of the corpus callosum for epilepsy, introduced the term intermanual conflict to refer to a dissociative phenomenon seen in the early postoperative period, in which one hand (or limb) acts at cross purposes to the other. One patient was observed buttoning up his shirt with one hand while the other hand was coming along right behind unbuttoning it. In performing the Jendrassik maneuver, the left hand pushed the right hand away rather than clasping it.

Beukelman et al $^{11}$ (ruptured ACA aneurysm surgically clipped) - When the patient placed a sock on a table with his right hand preparatory to putting it on his foot, the left hand picked up the sock and placed it back in its original position. In attempting to put a shoe on the left foot, when the right hand lifted up the left leg with the hand posterior, the left hand forcefully pushed the left leg down again, pressing the foot against the floor. The patient referred to his left foot as his 'dumb foot'. After combing his hair with the comb in his right hand, when he tried to place the comb in his left hand, the left hand pulled away. On the written command 'touch the spoon with your left hand', he picked up a key on four consecutive attempts. He said 'I'm trying to pick up the spoon. I don't know why I keep picking up the key!'

Goldberg et $\mathrm{al}^{12}$ (left ACAinfarction) - Under the designation "alien hand", two cases are described whose behavior differed from that of previous cases. In the first patient, the right hand would reach out spontaneously, grab hold of objects such as a doorknob and be unable to release the grip voluntarily. The 
patient was unable consciously to inhibit this behavior. On one occasion when removing her glasses with the left hand, the right hand came up to keep them on. The right hand tended to perseverate in acts it undertook. In the second patient, a strong grasp reflex in the right hand was associated with a tendency to carry out unintended activities, for example, picking up a pencil that happened to be on the table and scribbling with it involuntarily. The abnormal activities differed from those described so far and included reaching out, grasping, groping, grasping with inability to release, perseveration and utilization behavior. They are related to disturbances of frontal lobe function rather than to dyspraxia.

Mori and Yamadori ${ }^{13}$ (left ACA infarction) - The patient could not help grasping a familiar object such as a comb, pencil or toothbrush placed before her and using it appropriately with her right hand against her will. The authors called the abnormal behavior Compulsive Manipulation of Tools. A grasp reflex and an instinctive grasp reaction were present.

Gelmers ${ }^{14}$ (right ACAinfarction) - The patient did not initiate conversation. He reached out with his left arm and was unable to release his grip voluntarily. He perseverated in actions using his left hand, for example, using a knife and fork at meals, and handling a comb or electric razor. Purposive movements occurred independent of conscious volition. There was a strong grasp reflex on the left. There was a striking left facial weakness on laughing. The author deliberately avoided the terms 'alien hand'and 'intermanual conflict'.

Watson and Heilman ${ }^{15}$ (ACA infarction) - During recovery the patient complained that her two hands 'fight each other'. When she held an envelope, each hand independently and simultaneously tried to hold it and release it so that she would tug at the envelope, sometimes for as long as 10 minutes. Her family observed her taking one blouse out of the closet with the left hand, another one with the right hand. She put her left arm in one blouse and her right arm in the other. The left hand pulled the right blouse off and the right arm put the blouse back on. On another occasion she put her right arm into a sweater sleeve and the left arm started taking the sweater off. She once opened a cabinet door with her left hand, reached in with her right hand only to have her left hand close the door on her right arm. There was no grasp reflex. The authors regarded these activities as AHP.

Banks et al ${ }^{16}$ (Penetrating bullet wound to the frontal brain) The 51-year-old victim developed uncontrollable movements of the left arm and hand. She noticed that the hand tenaciously grasped objects in its vicinity, picked and pulled at her hair and clothing and even grasped her throat while she slept. There was bifrontal encephalomalaci greater on the right side with a lucency in the anterior part of the corpus callosum. The behavior was classed as alien hand.

Goldenberg et $\mathrm{al}^{17}$ (ruptured ACA aneurysm with surgical clipping) - The patient, when asked to pour water from a pitcher into a glass with her left hand, drank from the pitcher. When doing it with the right hand, the left hand also came over to the pitcher and the patient drank from the pitcher. When the left hand was prevented from interfering, the right hand poured water into the drinking glass. The patient often referred to her left hand as if it were a nasty child who 'always pursues his will until he gets punished'. She knew it was her own hand and denied any feeling of strangeness (alien hand). Withdrawal of objects held in the left hand sometimes disturbed bimanual tasks like cutting paper or sewing. When transferring an object from the left to the right hand, the left hand withdrew the object and held it tight. Touching either palm elicited grasping. The degree of hydrocephalus was in the symptomatic range.

Watson et al ${ }^{18}$ (left ACAinfarction) - The patient noticed that if he wanted to pick up an object such as a cup of coffee he would 'have to tell my hand to pick it up'. The right hand tended to cling to objects. Occasionally his right hand did things of which he was unaware.

Levin et $\mathrm{al}^{19}$ (ruptured ACA aneurysm with surgery) - The patient described competitive movements in which the left limb would tend to undo the action of the right limb. When the right hand was holding a newspaper open, the left hand would close the page. At mealtime the left hand refused to transfer a fork to the right hand. 'The left hand does not do what I want it to do.' The left hand would turn a tap off after the right hand had turned it on. When walking forward, the left leg would sometimes step back. Coordination of the lower extremities in dancing was impaired.

McNabb et $\mathrm{al}^{20}$ (left ACAinfarction - three cases) - The first patient showed markedly impaired bimanual coordination and she was unable to do up buttons in dressing or use a knife and fork simultaneously in eating. The left hand or arm underwent semi-coordinated movements while the patient was speaking or distracted. The right hand showed an uncontrollable tendency to reach out and take hold of objects which could not be released. The right hand interfered with tasks being performed by the left hand causing the patient to wedge the right hand between her legs to restrain it. In the second patient, tasks involving the coordinated use of both hands, such as eating or dressing, were severely impaired, the two hands appearing to act independently. At times the right hand would interfere with tasks being performed by the left hand. The disturbances in case three were much the same as in case two. When attempting to write with the left hand, the right hand would reach over and attempt to take the pencil from the left hand. The abnormalities were included in the categories alien hand and loss of bimanual coordination. The Bereitschafts potential was studied in the first patient.

Leiguarda et $\mathrm{al}^{21}$ (ruptured ACA aneurysm - three cases) The first patient put on her glasses with the right hand, only to have the left hand remove them. In the third patient, the left hand prevented the right hand from opening a case. When the patient was asked to write with the left hand, the right hand took the paper away and dropped it on the floor. Forced grasping was prominent.

Loring et $\mathrm{al}^{22}$ (complete surgical callosotomy) - Intermanual conflict was found only during neuropsychological assessment, for example, in visuoverbal and visuospatial tasks involving the two half-fields.

Tanaka et $\mathrm{al}^{23}$ (ruptured ACA aneurysm with surgical clipping) - By the third postoperative week, the patient's wife noticed peculiar movements of his left hand. As he picked up his cup with his right hand, he involuntarily picked up his wife's cup simultaneously with his left hand. As he read greeting cards held in his left hand, he tried to take them one by one with his right hand. His left fingers clung to the cards making it difficult for the right hand. After washing his hands he turned the tap off with his 
right hand only to turn it on again with the left. When finishing buttoning up his shirt using both hands, he found himself undoing the buttons with the left hand. 'My left hand will not do what I want it to.'There were no grasping or groping movements of the hands or feet.

The authors described four types of peculiar motor behavior in the patient's left hand. 1) When a task was performed with the right hand, the left hand would carry out identical movements; for example, when the right hand picked up an object, the left hand would come over and grasp it involuntarily. 2) The left hand acted at cross-purposes with the right hand interfering with the task; for example, when taking down his underpants with the right hand the left hand would suddenly reach down and raise them. 3) When he was trying to perform a task with the right hand, the left hand would carry out a different task; for example, when picking up his trousers from the floor with his right hand, the left hand might unbutton his shirt. 4) In tasks requiring the use of both hands, he could not move the left hand at will; for example, on the request to form interlocking circles with the thumb and index finger of each hand, the left hand withdrew as the right hand approached it. Although the title of their paper was "Diagonistic Dyspraxia", the authors noted that in the past, several different manual automatisms had been described under the terms "alien hand", "intermanual conflict" and "diagonistic dyspraxia". A special feature of their paper was the measurement of the Bereitschafts potential in their patient, finding it attenuated over the right hemisphere in the acute stage, and restored to normal after recovery, incriminating the right supplementary Motor Area.

Della Sala et $\mathrm{al}^{24}$ (ruptured ACA aneurysm with surgical clipping) - After a period in coma, improvement occurred and the patient was examined one year later. The right hand carried out unwilled actions. With her right hand the patient picked up an excessively hot cup of coffee, an action the left hand tried to stop. In response to genital itching, the patient scratched immodestly, the left hand again attempting to prevent the action. At times the right hand would interfere with the normal activities of the left hand. The patient could trust the left hand but the right hand 'always does what it wants to'. The patient consciously willed only what the left hand was doing while what the right hand did was always unexpected. At times she sat on the right hand to prevent it from interfering. She was always aware that the wayward right hand belonged to her. The right hand showed tonic grasping. The authors discussed the variety of dyspractic disorders reported in the literature and the possible inappropriateness of the various terms, suggesting a new designation, the 'anarchic hand' to express the complete autonomy of the arm and its disruptive effect on daily activities.

Gottlieb et $\mathrm{al}^{25}$ (presumed ACA infarction - two cases) - In the first patient, three types of involuntary activity of the left hand occurred: 1) The left hand interfered with activities initiated by the right hand. For example, when the right hand turned pages of a book in one direction, the left hand turned them back, or when the right hand opened a drawer, the left hand would close it. 2) In bimanual tasks the left hand acted before the right hand completed its task. For example, closing a box lid with the left hand before the right hand had finished withdrawing a cigarette, or while eating, picking up meat with the fork before the right hand had finished cutting it. 3) The left hand acted independently and unwilled in reaching to take hold of nearby objects while the patient was engaged in another task such as talking or reading. For example, he would pick up a pencil or cigarette and even use them, or unnecessarily lift a hot pot from the stove or manipulate a lever handle while driving. The presence or not of reflex grasping was not mentioned. In the second patient, the left hand did the opposite of what the right hand was doing, for example, unbuttoning a shirt with the left hand as the right hand buttoned it up or pushing away a cup of coffee with the left hand as the right hand drew it closer.

Feinberg et $\mathrm{al}^{26}$ (left ACA infarction) - Present were groping movements and a prominent grasp response that was not released promptly.

Trojano et $\mathrm{al}^{27}$ (right ACAinfarction) - The patient exhibited left ideomotor apraxia, groping, compulsive manipulation of objects and lack of coordination in bimanual tasks.

Papagno and Marsile ${ }^{28}$ (ruptured ACA aneurysm with surgical clipping) - Severe intermanual conflict was present; the right hand lowered the pants, the left hand pulled them up; the right hand paid for an item in a store, the left hand withdrew the money; while purchasing something else, the left hand picked up an orange; while the right hand was in a drawer, the left hand closed the drawer. The left hand acted 'cheeky'and was referred to as 'she' and 'always trying to anticipate my action'.

Giroud and Dumas ${ }^{29}$ (callosal infarction) - The authors studied eight cases of callosal infarction, finding callosal disconnection in five and the alien hand in two.

\section{THREE CASES FROM THE OLDER LITERATURE}

Liepmann ${ }^{30}$ in his famous case of the Regierungsrat, in which the left cerebral hemisphere was the site of infarction, recorded that the patient's wife observed that when the patient scratched himself on the nape of the neck with the left hand, the right hand came up to help. During testing when asked to pick up an object with the right hand, the right hand approached the object and paused. In that moment the left hand came over to approach the object and the right hand then seized the object just before the left hand reached it and the object was presented to the examiner with both hands. Also, when the patient wanted to select something with the right hand, the right hand would seize the left hand, pull it to the midline and fold the hands in one another. The author noted that the associated movements which the patient made with the right hand when the left hand was used and which were so prominent at one time as to interfere, later decreased significantly. The patient made loud smacking sounds with the mouth.

Goldstein $^{31}$ (right ACA infarction) - During the patient's recovery from the left-sided weakness, she said that her left arm did not belong to her but did what it wanted to. Once it seized her by the throat and choked her, requiring force to be released. She unintentionally tore the bed sheets. When the left hand took hold of something the grip could not be relaxed. On taking a drink the left hand clung to the glass and emptied it. The patient said 'I hit it and told my little hand to behave yourself' (laughing). 'There must be a mischievous imp in my hand.'In picking up an object the right hand took it and placed it in the left hand and no further manipulation occurred. The right hand tended to hold the left hand and direct it like an inanimate object. When the left hand 
held the bed covers and was unable to let go, the patient said 'I don't grip them, the hand does.' The left arm was severely dyspractic and there was a prominent forced grasp reaction.

Sweet $^{32}$ (ruptured ACA aneurysm) - The patient noticed an inability to release her grip on anything she picked up with her right hand. On instruction to place her left index finger on the tip of her nose, the finger instead entered her mouth. 'That's funny; why won't it go up to my nose?'The left hand did not hinder the right hand on bimanual tasks.

\section{Group II: Alien HAND PHENOMENA IN CBD}

CBD is a slowly progressive, irreversible 'degenerative' cerebral process, usually beginning between the ages of 60 and 70 and characterized in its advanced stages by dyspraxia and rigidity that had involved one limb after another, as well as the orofacial region. In addition, the clinical picture includes loss of fine movements, slowness, clumsiness, dystonia, myoclonic jerking, action tremor, hyperactive tendon reflexes and impaired eye movements. The duration is 5-14 years. Pathologically, the anterior parietal and posterior frontal cortex show severe convolutional atrophy. Microscopically, a highly typical unique destructive change involves the cortex with loss of nerve cells in cortical layers two and three, and advanced gliosis in the deeper layers resulting in status spongiosus. Subcortical demyelination is variable. Remaining cell bodies are swollen and pale-staining (achromasia). Chronic cell loss and gliosis frequently involve the globus pallidus, substantia nigra, thalamus and other subcortical structures.

The nosological status of CBD is under debate at present, especially its relationship to Pick's disease. Classical Pick's disease shows the same distinctive unique microscopic cortical pathology which in itself is strong evidence that CBD and Pick's disease are in the same spectrum. As a syndrome, CBD could be referred to as parietofrontal Pick's disease. Cases of Pick's disease in which frontotemporal atrophy was combined with parietal lobe atrophy have been reported. ${ }^{33,34}$ A convincing case of parietal Pick's disease was presented by Cambier et al. ${ }^{35}$ Kertesz $^{36}$ has marshalled the evidence favoring the umbrella view of Pick's disease.

In the following review, only the neurological findings related to the AHPwill be included; a description of the remainder of the neurological picture is beyond the present scope.

Movement abnormalities consistent with alien hand were described in two of the first three patients with CBD originally reported by Rebeiz et $a^{37}$ When the first patient used her right hand for objects on her left side the left hand would join in. At the dining table her mouth opened involuntarily when another person brought food to his mouth. The second patient became unable to button his shirt cuffs or tie his shoes because the left hand 'kept getting in the way of the right hand'. In a previous note $^{38}$ uncontrollable elevation and abduction of the limbs coming on during attempted motor activity, were described.

In the first patient studied by Sunohara et al, ${ }^{39}$ mirror movements and perseverations were prominent. There was a marked grasp reflex. In the second patient, mirror movements occurred. Alien hand phenomenon, not further described, were present in three of six cases of Riley and Lang. ${ }^{40}$ The patient of Gibb et $\mathrm{al}^{41}$ noted that his left hand had a curious tendency to levitation and the fingers wandered 'like the tentacles of an anenome'. Riley et $\mathrm{al}^{42}$ found AHPin 10 of 15 cases of CBD, two pathologically studied. The abnormalities included repetitive hand movements such as taking eye-glasses off only to replace them, putting tissues in a purse and then removing them again, and repeatedly raising one hand to the face to touch the mouth or the eyes. Levitation of the left arm without awareness occurred and there was a tendency for an arm to drift off and assume odd postures especially when the eyes were closed or attention was diverted. Sawle et al, ${ }^{43}$ in six patients with clinically diagnosed CBD, found an alien hand in three instances and an alien leg in one case. In the fifth patient, the left hand would involuntarily wander around grasping hold of objects and interfere with actions of the right hand. In the sixth patient, the right arm would wave around on its own and grasp hold of nearby furniture. Doody and Jankovic ${ }^{44}$ included five CBD patients with AHP.

Rinne et $\mathrm{al}^{45}$ found AHP in 14 of their 36 cases. An arm wandered uncontrollably, sometimes crossing the midline and interfering with the movement of the contralateral limb and at times grasping objects. A limb, in one case the leg was described as having a mind of its own or 'it just does not do what I want it to do'. Some patients described their affected limb as being foreign to them, 'it does not belong to me', but others felt the limb to be theirs but beyond their control. Kompoliti et $\mathrm{al}^{46}$ in an analysis of 147 cases of presumed CBD, AHP were recorded in $42 \%$. The nature of the abnormal movements was not described. Boeve at $\mathrm{al}^{47}$ found AHPin only two of 13 cases. Graham et $\mathrm{al}^{48}$ found a tendency for their patient's right arm and leg 'to take on a life of their own'. For example while attempting to wash his head he would find the right hand rubbing his chest; if he concentrated on a task such as writing, his right leg often rose involuntarily. Hanna et $\mathrm{al}^{49}$ determined that 33 of 66 patients with CBD showed the features of alien hand syndrome when subjective reports and objective signs were both present.

This summary indicates that AHP are common in CBD. A precise description of the criteria for the identification of AHP was usually not provided. Also the details of the clinical behavior are generally missing, precluding any attempt at a physiological analysis of the underlying dyspraxia.

Similar abnormalities mentioned in the older literature are of interest. Lhermitte et $\mathrm{al}^{50}$ described two dyspractic cases that could well qualify for the diagnosis of CBD. In both cases there was bilateral synkinesis in miming. The first patient was embarassed by his right arm which wandered like a 'corps étranger'. When taking food to his mouth with a fork in his left hand, the right hand brought the knife towards his eye with the risk of injury. In the second patient, pointing to the right or left side with the left hand elicited imitative movements of the right hand. Frequently a movement not possible voluntarily was executed in a synkinesis. Lhermitte and Trelles ${ }^{51}$ described a dyspractic man who complained 'I have lost my left side. I don't understand how that happened'. Neuropathological examination showed marked gyral atrophy limited to the parietal lobes bilaterally. Their patient is a good candidate for the first report of CBD or parietofrontal Pick's disease.

\section{Group III: AlIEN HAND CASES OF SPECIAL TYPES}

Included here are somewhat unusual cases that differ sufficiently from the cases already discussed to warrant being described separately. 


\section{Sensory type}

Levine and Rinne ${ }^{52}$ (occlusion of the right posterior cerebral artery) - Following a stroke, the patient showed a severe sensory loss on the left side of the body due to thalamic infarction and, in addition, a left homonymous hemianopia due to calcarine infarction. The patient was subject to episodic, ballistic, ataxic spontaneous movements of the left arm and leg. The patient complained that the arm moved on its own and she treated it as a misbehaving child. The source of the abnormal movements was not identified although exaggerated postural adjustments associated with movements of the opposite side could have been a factor. Because of the sensory loss, the patient was unable to feel the left limbs move and because of the hemianopia, could not see the limbs. This form of alien hand is unrelated to the dyspractic type.

Ventura et $\mathrm{al}^{53}$ (thalamo-capsular hemorrhage) - The patient had a left hemiplegia and a severe sensory loss but no callosal lesion. The movements were mainly an imitative synkinesis but levitation also occurred at night. The authors considered a subthalamic origin for the movements. It is likely that limbs with severe sensory loss without paralysis are subject to aimless movements as part of unappreciated bimanual activity. Ay et $\mathrm{al}^{54}$ found much the same in their patient as in the patient of Levine and Rinne. ${ }^{52}$ The involved arm resembled an 'unguided missile'.

\section{Seizure related}

Rubboli et $\mathrm{al}^{55}$ found epileptic seizures arising in the right medial frontal region caused left forced grasping, grasping of body parts, making a fist and inability to speak. Leiguarda et $\mathrm{al}^{56}$ studied four patients with transient episodes: patient one had left medial frontal focus causing grasping movements of the right hand; patient two had right medial frontal lesion causing left grasping movements; patient three had left parietal postsurgical lesion resulting in spontaneous uncontrollable movements of the right arm; patient four had right parietal hematoma causing episodes of involuntary elevation and jerking of the left arm. Including the episodic, brief, involuntary movements of seizures in the category of alien hand is hardly warranted except possibly for longer lasting postictal phenomena.

\section{Related to transient ischemic attack (TIA)}

Andre and Domingues ${ }^{57}$ (?TIA in the ACA territory) - raise the interesting question whether a TIA might cause a transient alien hand. Their patient made automaton-like gestures of the left arm and hand, lasting 5-10 min, and associated with weakness of the left leg.

\section{Miscellaneous}

Dolado et $\mathrm{al}^{58}$ (bilateral parietal infarcts) - The left hand interfered with the right hand, for example grasping a razor or unbuttoning clothing. Uncontrollable movements of the left hand were triggered by movements of the right arm which functioned normally. A satisfactory interpretation was not made.

\section{Group IV: Personal observations in CBD}

In the personally studied patient with left ideomotor apraxia caused by a ruptured ACAaneurysm, ${ }^{3}$ the left arm, whose mirror movements accompanied normal movements of the right hand, was referred to by the patient as 'my buttinski'. 'The left hand tries to get into the act'. Subsequently, on the neurological service of the Massachusetts General Hospital, any similar involuntary interactions of the right and left hands were colloquially called the 'buttinski phenomenon'. It was encountered in several cases of CBD and the following is an account of our experience.

Patient 1. (Pathologically verified) - The patient was a woman whose downward course extended over a period of 14 years. The legs were involved first, the arms six years later. At $7 \frac{1}{2}$ years when she could no longer walk, dress, button her clothing or write, the left arm was more impaired than the right. 'It won't do what I tell it to.'When her left hand grasped something, there was difficulty letting go. The right hand saluted well. When the left hand saluted, the right hand went up at the same time. When throwing a kiss with the left hand, the right hand went up at the same time. When miming the use of a toothbrush with her left hand, the right hand 'got into the act'unless it was held down on the bed.

After failing attempts to mime combing her hair with the right hand or playing the violin, she said 'I don't know what my hands are doing. I' $m$ no longer in control.' When she moved either arm, the other tended to do the same. In all attempted movements of the left arm, the right arm underwent extensive movements of the instructed type; for example, while attempting to touch her nose with the left hand, and hesitating, the right hand came up and touched the nose. On trying to touch the thumb to the fingers on the left hand and failing, the right hand came over and palpated the left fingers. As the patient engaged in conversation, the right hand continually palpated the bed covers, moved down to the region of the left knee and lifted the patient's skirt, slightly exposing the patient.

When joint position sense was being tested with the patient's left arm resting on the arm of the wheelchair, the arm was pulled back until the elbow was posterior to the plane of the body. The same reaction occurred when testing vibration sense and the brachio-radialis reflex. On attempting to pat the dorsum of the right hand with the left hand, the right hand pulled away as the left approached. When the examiner placed the patient's left hand on her right hand, the left arm pulled away forcibly. On attempting to touch the thumb to the fingers of the right hand and failing, the right hand was pulled away by a backward movement at the shoulder. The left arm tended to become lodged under the arm of the wheelchair almost defying attempts at extricating it. Turning the pages of a newspaper produced a crumpled mass. She could not clap or mime sharpening a pencil. She had awakened at night with her right arm in the grasp of the 'paralyzed' left hand. On attempting to flex the right leg, it abducted and rolled over the side of the bed. On shifting her position in bed, her body went in the opposite direction and the legs scissored. After 12 years the left fingers still tended to cling to objects. The patient's mind was relatively preserved.

In summary, the AHP included duplicate movements of the opposite arm, bilateral participation in unilateral tasks, pulling away of each arm and forced grasping on the left. The upper limbs are skilled and often act in unison (dressing, eating, washing, using tools etc). Hence their potential for complex dyspractic performance exceeds that of the legs and body.

Patient 2. (Pathologically verified.) - A woman whose illness began with involvement of the left leg, then of the right leg and 
left arm was examined during the fourth year of her six year course. She was unable to dress or feed herself. She was alert and cooperative. On request she touched her nose with her right hand. When asked to do it with the left hand, both hands came up. When asked to take an object with her left hand, the right hand always came over and took the object. This occurred with a comb and a pencil and in shaking hands. If, in these tasks, the right hand was restrained on the bed and she took an object with her left hand, when the right hand was released, it came over and took the object.

She could not mime combing her hair with the right hand but with a comb in her right hand she combed both sides of her head. She did not take hold of the comb with the left hand. When asked to mime the use of a hammer, she leaned over, took hold of the examiner's hand and patted it. She did not mime or copy sawing but stated that the examiner was sawing. She correctly held a pencil in her right hand and very slowly drew her name legibly.

In several situations, a complex stereotyped response was substituted for the act requested. When asked to hold one arm out in front while she was lying in bed, she sat up and triple flexed both legs, bringing the knees up to the abdomen and lifting her skirt immodestly. She then brought her left hand up to her throat and her right hand up to her forehead or hair. Next, she reached over with her right hand to take a handkerchief paper tissue from its container on her bedside table. She moved the box around for 15-20 seconds. She then took hold of the hem of her skirt lifting it to further expose herself. At this point she might pick up a small bit of lint from the bed or pick up an imaginary something from the region of her knee. The patient, at all times, could repeat each request and stated that at the time she was unable to reposition her skirt.

When asked to show her teeth, the left hand came up to her throat, while the right hand came up to the region of the mouth as the patient extruded her lower dental plate into her right hand. She smiled. When the plate was replaced and the same request made again, another extrusion occurred followed by the entire stereotyped performance just described. While sitting erect in bed, she was asked to bend forward in order to touch the examiner's index-finger with her nose. Both hands came forward to hold the finger and there followed another full stereotyped performance. On command she lifted the right leg up from the bed. When the same was requested of the left leg, the same stereotypy was repeated. It occurred again when she was asked to cross her legs or turn on her side.

The family said that when trying to have the patient lean forward while seated, in order to have her hair washed, her body was thrust backward with great force.

In addition to mirror movements, interference of one hand with the other, and contrary body dyspraxia, the patient exhibited prominent ideational dyspraxia, accounting for the complex stereotyped performance and remarkable repetition (perseveration). This strange, 'foreign', unwilled behavior outdistances the restricted concept implicit in alien limb phenomena.

Patient 3. (Pathologically verified.) - The patient, aged 64, presented because of a complicated, advancing parkinsonism of four years'duration. He reported that the more affected left hand got in the way of the less affected right hand. When he used the right hand in tasks, the left hand tended to approach it. When writing with the right hand, the left hand underwent gyrations. The patient thought that if he avoided holding the paper with the left hand it would not gyrate. When walking, the left arm tended to flex at the elbow, become adducted across the front of the body and even rise in the air. There was no tendency for the left hand 'to get into the act' when he ate or reached out. In the gymnasium when he lifted weights with the right hand, the left hand also rose. When he squeezed the examiner's hand with the right hand, the left arm became tense, flexed at the elbow and the fingers and wrist underwent 'athetotic' movements. When he approximated his knees forcibly, the left hand rose in the air. Leg movements precipitated even more exaggerated adventitious movements of the left arm.

At rest there was little or no movement of the left fingers. As the patient talked or moved, the left fingers underwent 'athetotic' gyrations. The patient had noted these adventitious movements early in the course of his illness, when he had terrible difficulty putting on a glove or putting his hand into the sleeve of a coat. Also in earlier days of his illness, the left hand tended to cling to doorknobs but this had ceased. A grasp reflex was present on the left. In bed at night he often felt that he had no left arm. As an aside it may be mentioned that the patient gave a history of being struck by lightning three times.

The main abnormalities included mirror movements, a minor tendency to bimanual interference, complex associated movements of the left arm and hand, and by history, forced grasping. Intellectually, the patient was close to normal. Symptomatic normal pressure hydrocephalus may have contributed to his bladder and walking difficulties.

Patient 4. (Pathologically verified.) - The patient, aged 65, was in the fourth year of his illness which began with rigidity and tremor of the right upper extremity. Later the right leg, left leg and left arm became involved, in that order, rendering him totally helpless, immobilized by rigidity and dyspraxia. His mind was largely spared. 'I'm not crazy, I know what I want to say and do but my body won't respond. It's like a short circuit mental force against a physical resistance.'When a movement went awry, he would say, 'What the hell am I doing?'

'When I bless myself, my left hand goes to the top of my head and scratches there. I don't want to do that but it seems to have a mind of its own. When I want to take off my glasses, I take out my teeth instead.' The left hand usually made a movement resembling the intended act rather than something quite foreign. When attempting to touch his finger to his nose, as it rose and wavered, he reached forward with his open mouth as if to suck on his index finger. When the nurse put on his eyeglasses, he opened his mouth wide. When he ate he brought his face close to his food or plate.

There was a tendency for the patient to repeat the last statement of the examiner, for example, 'Is it difficult to do things with your left hand?'he replied 'It is difficult to do things with my left hand.'There was a grasp reflex on the right.

The limited performance was in keeping with ideational apraxia combined with rigidity. The visual sucking or oral response was striking. The motor errors were clearly 'unwilled' and unintended.

Patient 5. (No pathological examination.) - The patient, aged 75 , first became symptomatic five years before. His arms were more affected than the legs. Speech was barely comprehensible. 
He was helpless and could perform almost no tasks with his hands. Mentation and memory were relatively normal.

He could not mime or copy hand and finger movements. In failing, there was a tendency for the two hands to come together with the fingers of his right hand feeling the index finger and thumb of the left hand. On request, he slowly placed his right hand on the top of his head. On command to place the left hand on the top of his head, both hands were raised in mirror fashion. When the right hand was restrained, the left hand could not perform the act on its own. On picking up an object with the right hand, the left hand interfered (butted in).

When asked to cross his legs while seated, the patient kicked off one slipper, then the other, rubbed his ankles or heels together and raised both legs high in the air, lifting his dressing gown up and exposing himself as he reached down with his right hand. This same performance was observed on three occasions. In all failed tasks, the patient could repeat the instructions given.

When asked to bend forwards, he leaned backwards. When he was asked to take a bow, he could bend forwards. When asked to straighten his legs, he flexed them. He could make some movements of brushing his teeth only when looking in a mirror but not otherwise.

There was a marked grasp reflex in each hand and in each foot. The patient tended to reach out toward everything in front of him. The patient seemed attracted to sights and sounds around him. Periodically there was very loud lip-smacking, once every two seconds, heard in the corridor. There was a tactile lip-pursing reaction bilaterally.

Basically the patient presented an array of ideomotor and ideational dyspractic acts, all uncontrollable and unintended. In addition, there were simpler mis-acts - mirror movements, intermanual interference, enabling synkinesis, reaching out and lip-smacking.

Patient 6. (No pathological examination.) - A 66-year-old, right-handed woman first noted difficulty writing and dealing cards two years before presentation. Function in the arms gradually failed until she no longer could feed herself, dress, bathe, take a pill, put on her glasses, use a purse, put on gloves or lace her shoes. She conversed normally and walked five miles a day for exercise.

'If I move the right hand, the left will try to follow.' When asked to touch her chin with her right hand, the left hand flew up to the chin as the right hand came up to the right cheek. This was despite the fact that the patient's usual position was sitting erect, very dignified with her chin in one hand. When asked to show her right thumb, the left hand twice came up briefly and showed the thumb. 'The left hand wants to take over when I do something, it wants to get into the swim. If I try too hard to do something, I can't do it.'

The patient conversed readily. She read aloud without error. She identified right and left, fingers and body parts correctly.

'When my left hand takes hold of something I can't let go of it. If I pick up a coffee cup with my right hand, I have no difficulty letting go, with the left hand, I do have difficulty.' On attempting to toss a ball, it could not be released. When asked to pick up a glass with the right hand, as the right hand reached out first, the left hand shot out but was pulled back. The patient had noticed that her right hand would often reach out for the wrong thing. Spontaneously she scratched her right ear with her right hand. A moment later when asked to perform a similar action, she hesitatingly brought the right hand up to the right cheek or eye.

Attempting to print an "N" with a pencil in her left hand was distinctly improved when she closed her eyes. When asked to draw an " $A$ " in the air, she closed her eyes and brought her left hand to her nose and then to one eye, saying 'Two sides down and one across.' When asked to draw an " $\mathrm{A}$ " in the air with her head and neck, she brought her left hand up to her nose and one eye. Next she closed her eyes and nodded once, then brought her right hand up and extended her neck. When the examiner drew an "O" in the air with his head and neck, she immediately recognized it.

The right hand took a comb from the left hand and could not pass it back to the left hand. 'I can't pass anything from one hand to the other.' 'When I reach to open the icebox, I reach from some distance. My mind tells me what to do. I try not to get there too fast.'When asked to point to the window with her left hand, she did so but the right hand moved also and adopted the position of pointing used by the left hand. When asked to wiggle the left index finger she raised the left hand, touched her nose, said 'no', brought up the right hand, then both hands were raised and all five fingers on the left hand were wiggled. On attempting to salute with the left hand, the right hand made a slight movement as the patient bent forward. She then reached straight out with the left arm. The left leg was then extended and after holding that position for two minutes, the patient placed her left fist against the left eye. A prolonged effort to comply characterized most attempts. At all times the patient could repeat the instructions correctly and assure the examiner that she understood what was requested.

While seated she was asked to move her left foot from side to side, to the right and then to the left. She stood up, did not move the legs, bent forward at the hips as she reached toward the right knee with the right hand as the left hand clasped her dressing gown. At this point she said she was unable to show disgust with her performance. At times a complex stereotyped, dyspractic performance was repeated when several successive attempts had failed, indicative of a tendency to perseveration. For example, when asked to make a fist with the right hand she leaned forward, crossed or uncrossed her legs, brought her left hand across the abdomen, extended the left leg and with her left hand lifted her skirt, exposing herself. Much the same performance then followed requests to touch the fingers to the thumb, comb her hair, pronate-supinate her left forearm on her left thigh or blow her nose. The aberrant movements continued as long as the patient persisted in trying to comply.Arm swing on walking was still present.

The patient tended to repeat the examiner's words, for example, 'Did you hear what I said?' 'Yes I heard what you said.'

In this case, the right hand was more impaired than the left hand. The AHP included mirror movements of the left hand, participation of the left hand in right hand tasks, contrary acts, reaching out, forced grasping with inability to let go, and unwilled complete ideationally dyspractic movements involving arms, legs, trunk and head and neck. The mis-movements were marked by slowness, pauses, aborted starts, and interrupted trajectories.

This patient was examined in 1963 when her state was 
designated 'universal dyspraxia'. The nature of her illness was not recognized at that time.

\section{DISCUSSION}

The types of errors included under the AHP may be divided into two main categories: I. Involving complex unwilled motor acts; and II. Simple quasi-reflex actions seen in normal infants.

I. Included under complex, unwilled motor acts: 1) The original alien hand, which is not a motor disorder but rather is a callosal disconnection sign. It is retained here to provide a niche for 'alienness'. 2) Intermanual conflict in which the leading hand performs an act which the other hand undoes - dressing, buttoning, opening a drawer, turning on a tap, turning the pages of a book etc. 3) Mirror movements in which the second limb performs essentially the same actions as the leading limb, without disturbing the performance. 4) Interference in which the opposite limb enters into the act being performed by the leading limb causing various degrees of interference or disruption. 5) Enabling synkinesis in which one arm can carry out an act only if both arms act together. 6) Reversal of complex acts - Stepping back instead of forwards, bending backwards instead of forwards etc. 7) Pushing aside in which one limb pushes the other limb aside, instead of cooperating.

II. Relatively simple unwilled, unskilled, quasi-reflex actions include: Reaching out, groping, grasping, grasping with inability to release (forced grasping, tonic innervation), withdrawal of a limb, compulsive utilization of tools, and utilization behavior. Oral reactions to tactile and visual stimuli are frequently associated.

Category I cases tend to fall in the realm of dyspraxia while Category II cases, in view of the simplicity of the motor acts, are of a different order. In many cases, disorders from both categories are represented. The discussion that follows pertains mainly to Category I disorders.

\section{Comment on bimanual activity}

Since the focus of interest is the hands and arms, some preliminary remarks on their underlying motor organization are in order. In daily life, the two arms regularly act in combination - bathing, dressing, undressing, eating, household tasks, use of tools, use of a purse, manufacturing, driving, typing, reading, athletics, musical performance etc. There are few strictly unimanual activities. There is a dominant or leading hand and a nondominant hand. Callosal disconnection syndromes demonstrate that skilled acts are normally directed for the most part, from the speech dominant hemisphere, the neural instruction to the nondominant hemisphere travelling via the corpus callosum and other commissures. Two entirely separate, mobile, skilled entities (the arms) performing in concert are controlled by a single directorship in the dominant hemisphere. The potential for disordered coordination as the result of brain damage to this finely coordinated system is great. Uncrossed descending pyramidal fibers provide a subsidiary pathway of uncertain capacity.

With this picture of cerebral motor function in mind, it may be a useful exercise to examine some of the AHP. For example when the right hand buttons a garment and the left hand involuntarily gets into the act and unbuttons it (intermanual conflict), the performance may be interpreted as a disturbance in the cooperation of the two hands. Normally both hands are used in both tasks. In buttoning, the right hand is the lead performer, in unbuttoning it is the left hand that leads. Instead of the two hands mutually cooperating, each hand acts separately, carrying out its own special skill, in succession. Use of the term 'conflict' may obscure the true nature of the error which consists in failure of the two hands to be coordinated temporally. Usually the left hand is the offender. The abnormal process may be interpreted as a partial disconnection. Likewise in reading, the left hand normally turns the pages in one direction, the right hand in the opposite direction. In intermanual conflict, the actions of the two hands are inappropriately linked, and each hand carries out its own special skill. There is only the appearance of conflict.

In mirror movements, action of one upper limb is accompanied by similar action in the opposite upper limb, usually the left in dextrals, producing bilateral action rather than unilateral. The main aberration consists of an unintended, unwilled performance by the left limb.

Simply stated, there appear to be two main types of disorder. In bimanual tasks the left limb tends to act unimanually; in unimanual tasks the response is bimanual, the left limb again performing unwilled. The other abnormalities listed in Category I can be interpreted as variations of this general proposition.

Although the underlying pathophysiology can be only vaguely envisaged, there is solid evidence that the pathological basis consists of damage to the supplementary motor area and the adjacent cingulate gyrus, usually in association with interruption of the anterior corpus callosum. (For a brief summary see $\mathrm{McNabb}$ et $\mathrm{al}^{20}$.) Why activity of the left upper limb is reduced in bimanual tasks and increased in unimanual tasks can only be surmised. In bimanual tasks, visual and tactile guidance are preserved but temporal synchrony is impaired. In unimanual tasks motor impulses subserving the dominant right upper limb reach the left upper limb, possibly as the result of damage to the right supplementary motor area, the left upper limb being incapable of acting on its own.

Future analysis of these disorders will require a more thorough examination of the clinical states seeking more details. The performance of the two hands on bimanual tasks must be explored. Also, since many tasks are virtually automatic, proceeding with minimal awareness, the patient's state of mind at the time of the performance should be carefully assessed. Patients must be questioned concerning movements that are judged to be willed vs unwilled, and what the terms mean.

\section{Willed and unwilled movements}

The abnormal movements described above touch on a subject of considerable theoretical importance, namely the nature of willed movements and 'the will', topics referred to by Liepmann $^{30}$ as he developed the doctrine of dyspraxia. The patients described in the foregoing review frequently noted that their aberrant movements were not under their control, that they were unintended, involuntary or unwilled. When a patient deliberately turns on a water tap with the right hand, and the left hand, on its own, turns the tap off, the patient will say that the first act was deliberate, the second act was unintended, involuntary. This dichotomy might provide an opportunity to examine some aspects of 'willed movement' and 'the will'. 
Libet $^{59}$ demonstrated that when humans make a movement, the associated cerebral electrical activity precedes the conscious decision to act by several hundred milliseconds. Presumably as the act unfolds, it is recorded in ideation, like a thought which is referred back slightly in time, and the individual gains the impression that he 'willed' the act. According to this thesis, motor behavior may be regarded as proceeding automatically, as a complex reflex without the action of 'will'. The neural activity that is then registered in ideation is felt as 'willed'.

Alien hand cases do not speak directly to this fundamental problem since the unwilled, unintentional acts do not occur on their own, but are part of another, usually greater willed act. The aberrant unbuttoning, turning off the tap, turning back the page, closing the cabinet door etc, are part of a willed act, the other part of which proceeded as intended. The abnormal part of the act is a special type of involuntary action that is termed dyspractic rather than being wholly involuntary like tremor or athetosis. Likewise, in ideational apraxia as illustrated in the personal cases two and five, which were previously described, the uncontrollable acts of a pattern unrelated to the requested action continued for minutes at a time but only as long as the patient 'tried' or 'willed' to perform the requested action. The fundamental question of whether there is a 'willed act' was not addressed.

While the overall performance in the alien hand cases may not apply to the question of 'free will', there remains for consideration the patient's distinction between the performance of one limb being willed and the performance of the other limb being unwilled, the latter acting on its own. The unwilled movement can be complex and well-executed, for example, unbuttoning. The patient is aware of the movement through sensory afferents. There is no ready way of accounting for the absence of conscious will within the precepts of conventional neurophysiology.

Turning again to the Libet-derived concept ${ }^{59}$ that the personal impression of 'will' follows the action rather than preceding it, in intermanual conflict the action of each arm would be executed satisfactorily with only the action of the right arm being recorded in ideation and thus becoming willed. The action of the left arm although well-executed is not recorded in ideation and fails to be interpreted as willed. The Bereitschafts potential, recorded over the superomedial frontal region, precedes decision-making and movement and may reflect a basic contribution to the impression of 'will'. It could be postulated that a lesion of one supplementary motor area prevents this basic component while still permitting well-executed movements of each arm, and the impression of 'will' on the side of the intact supplementary motor area. This would apply to bimanual and unimanual tasks. Tanaka et $\mathrm{al}^{23}$ found the Bereitschafts potential temporarily absent in the hemisphere opposite the alien hand. The ideational apraxia of CBD associated with parietal lobe atrophy would have quite a different mechanism, related to parietofrontal cortical disease. Libet's experiment in cases of CBD could be instructive.

Humans have the irrefutable conviction that each of us possesses a free will to act. The 'will' is a concept whose ideation is especially difficult to analyze by introspection. Most human activity proceeds rather automatically. When a decision is deliberated, ideation (thinking) is involved as one ponders whether or not to act. The ideation of pondering, however, is based on nervous system activity. If this assumption is followed to a reasonable conclusion, ultimately, nervous system activity must always precede. If this inference derived from elementary principles is correct, 'free will'cannot exist.

\section{REFERENCES}

1. Akelaitis AJ. Studies on the corpus callosum IV. Diagonist dyspraxia in epileptics following partial and complete section of the corpus callosum. Am J Psychiatry 1944;101:594-599.

2. Gazzaniga MS, Bogen JE, Sperry RW. Some functional effects of sectioning the cerebral commissures in man. Proc Natl Acad Sci 1962;48:1765-1769.

3. Fisher CM. Symmetrical mirror movements and left ideomotor apraxia. Tran Am Neurol Assoc 1963;88:214-216.

4. Schaltenbrand G. Discussion. In: Cerebral Localization and Organization. Schaltenbrand G, Woolsey CN. eds. Madison, University of Wisconsin Press, 1964.

5. Sperry EW, Gazzaniga MS, Bogen JE. Interhemispheric relationships: neocortical commissures; syndromes of hemispheric disconnection. In: Handbook of Clinical Neurology. Vinken PJ, Bruyn GW. eds. Amsterdam, North Holland. 1969; 4: 273-290.

6. Brion S, Jedynak CP. Troubles du transfert interhémisphérique (callosal disconnection) a propos de 3 observations de tumeurs du corps calleux. Le signe de la main étrangère. Rev Neurol 1972;126:257-266.

7. Bogen JE. The callosal syndrome. In: Clinical Neuropsychology, Heilman KM and Valenstein EV. eds. Oxford University Press, 1979: 308-359.

8. Wilson DH, Reeves A, Gazzaniga M, Culver C. Cerebral commissurotomy for control of intractable seizures. Neurology 1977;27:708-715.

9. Joynt RJ. Inattention syndromes in split-brain man. In: HemiInattention and Hemispheric Specialization. Weinstein EA and Friedland RP. eds. New York: Raven, 1977.

10. Barbizet J, Degos JD, Lejeune A, Leroy A. Syndrome de dysconnection interhémisphérique avec dyspraxie diagonistique au cours d'une maladie de Marchiafava-Bignami. Rev Neurol 1978;134:781-789.

11. Beukelman DR, Flowers CR, Swanson PD. Cerebral disconnection associated with anterior communicating artery aneurysm: implications for evaluation of symptoms. Arch Phys Med Rehabil 1980;61:18-23.

12. Goldberg G, Mayer NH, Toglia U. Medial frontal cortex infarction and the alien hand sign. Arch Neurol 1981;38:683-686.

13. Mori E, Yamadori A. Compulsive manipulation of tools and pathological grasp phenomenon. Clin Neurol (Japanese) 1982;22:329-335.

14. Gelmers HJ. Non-paralytic motor disturbances and speech disorders: the role of the supplementary motor area. J Neurol Neurosurg Psychiatry 1983;46:1052-1054.

15. Watson RT, Heilman KM. Callosal apraxia. Brain 1983;106:391403.

16. Banks G, Short MPA, Boller F, Kowal CD, Ratcliff G. Alien hand syndrome (AHS): role of callosal and frontal lobe lesions. Neurology 1984;34(suppl 1):86.

17. Goldenberg G, Wimmer A, Holzner F, Wessely P. Apraxia of the left limbs in a case of callosal disconnection: the contribution of medial frontal lobe damage. Cortex 1985;21:135-148.

18. Watson RT, Fleet WS, Gonzalez-Rothi L. Heilman KM. Apraxia and the supplementary motor area. Arch Neurol 1986;43:787-792.

19. Levin HS, Goldstein FC, Ghostine SY, et al. Hemispheric disconnection syndrome persisting after anterior cerebral artery aneurysm rupture. Neurosurgery 1987;21:831-838.

20. McNabb AW, Carroll WM, Mastaglia FL. "Alien hand" and loss of bimanual coordination after dominant anterior cerebral artery territory infarction. J Neurol Neurosurg Psychiatry 1988;51:218222.

21. Leiguarda R, Starkstein S, Berthier M. Anterior callosal hemorrhage. A partial interhemispheric disconnection syndrome. Brain 1989;112:1019-1037. 
22. Loring WD, Meador KJ, Lee GP. Differential-handed response to verbal and visual spatial stimuli: evidence of specialized hemispheric processing following callosotomy. Neuropsychologia 1989;27:811-827.

23. Tanaka Y, Iwasa H, Yoshida M. Diagonistic dyspraxia: case report and movement related potentials. Neurology 1990;40:657-661.

24. Della Sala S, Marchetti C, Spinnler H. Right-sided anarchic (alien) hand: a longitudinal study. Neuropsychologia 1991;29:11131127.

25. Gottlieb D, Robb K, Day B. Mirror movements in the alien hand syndrome. Amer J Phys Med Rehabil 1992;71:297-300.

26. Feinberg TE, Schindler RJ, Flanagan NG, Haber LD. Two alien hand syndromes. Neurology 1992;42:19-24.

27. Trojano L, Crisci C, Lenzillo B, Elefante R, Caruso G. How many alien hand syndromes? Follow-up of a case. Neurology 1993;43:2710-2712.

28. Papagno C, Marsile C. Transient left-sided alien hand with callosal and unilateral fronto-mesial damage: a case study. Neuropsychologia 1995;33:1703-1709.

29. Giroud M, Dumas R. Clinical and topographical range of callosal infarction: a clinical and radiological correlation. J Neurol Neurosurg Psychiatry 1995;59:238-242.

30. Liepmann H. Der Krankheit der apraxie, motorischen asymbolie. Monatschr Psychiatrie Neurol 1900;11:15-44, 102-132, 182-197.

31. Goldstein K. Zur lehre von der motorischen apraxie. Z Psychol Neurol 1908; 11:169-187.

32. Sweet WH. Seeping intracranial aneurysm simulating neoplasm syndrome of the corpus callosum. Arch Neurol Psychiatry 1941;45:86-104

33. Braunmühl A. Uber Stammganglien Veränderung bei Pickschen Krankheit. Z Neurol Psychiatry 1930;24:214-221.

34. Aronson SM, Aranson BE. Clinical Neuropathological Conference Dis Nervous System 1973;34:124-130.

35. Cambier J, Masson M, Dairou R, Henin D. Étude anatomo-clinique d'une form parietale de maladie de Pick. Rev Neurol 1981;137:33-38

36. Kertesz A. Frontotemporal dementia, Pick's disease and corticobasal degeneration. One entity or three? Arch Neurol 1997;54:1427-1429.

37. Rebeiz JJ, Kolodny EH, Richardson EP Jr. Corticodentatonigral degeneration with neuronal achromasia. Arch Neurol 1968;18:20-33.

38. Rebeiz JJ, Kolodny EH, Richardson EP Jr. Corticodentatonigral degeneration with neuronal achromasia: a progressive disorder of late adult life. Trans Am Neurol Assoc 1967;92:23-26.

39. Sunohara N, Mano Y, Muramoto O, Ando K, Satoyoshi E. Apraxiarigidity syndrome. Clin Neurol 1981;21:587-596 (In Japanese)

40. Riley DE, Lang AE. Corticobasal ganglionic degeneration (CBGD): further observations on six additional cases. Neurology 1988;38:( suppl 1):360.

41. Gibb WRG, Luthert PJ, Marsden CD. Corticobasal degeneration. Brain 1989;112:1171-1192.
42. Riley DE, Lang AE, Lewis A, et al. Cortical-basal ganglionic degeneration. Neurology 1990;40:1203-1212.

43. Sawle GV, Brooks DJ, Marsden CD, Frackowiak RSJ. Corticobasal degeneration. Brain 1991;114:541-556.

44. Doody RS, Jankovic J. The alien hand and related signs. J Neurol Neurosurg Psychiatry 1992;55:806-810.

45. Rinne JO, Lee MS, Thompson PD, Marsden CD. Corticobasal degeneration. A clinical study of 36 cases. Brain 1994;117:11831196.

46. Kompoliti K, Goetz CG, Boeve BF, et al. Clinical presentation and pharmacologic therapy in corticobasal degeneration. Arch Neurol 1998;55:957-961.

47. Boeve BF, Maraganore DM, Parisi JE, et al. Pathologic heterogeneity in clinically diagnosed corticobasal degeneration. Neurology 1999;53:795-800.

48. Graham NL, Zeman A, Young AW, Patterson K, Hodges JR. Dyspraxia in a patient with corticobasal degeneration: the role of visual and tactile inputs to action. J Neurol Neurosurg Psychiatry 1999;67:334-344.

49. Hanna P, Vanek ZF, Jankovic J. Alien limb in cortical-basal ganglionic degeneration. Neurology 1999;52(suppl 2):A226.

50. Lhermitte J, Lévy G, Kyriako N. Les perturbations de la représentation spatiale chez les apraxiques - a propos de deux cas cliniques d'apraxie. Rev Neurol 1925;2:586-600.

51. Lhermitte J, Trelles JO. Sur l'apraxie pure constructive. Encéphale 1933;28:413-444.

52. Levine DN, Rinne WE. Opticosensory ataxia and alien hand syndrome after posterior cerebral artery territory infarction. Neurology 1986;36:1094-1097.

53. Ventura MG, Goldman S, Hildebrand S. Alien hand syndrome without a corpus callosum lesion. J Neurol Neurosurg Psychiatry 1995;58:735-737.

54. Ay H, Buonanno FS, Price BH, Le AD, Koroshetz WJ. Sensory alien hand syndrome: case report and review of the literature. $\mathbf{J}$ Neurol Neurosurg Psychiatry 1998;65:366-369.

55. Rubboli G, Gardella E, Meletti S, et al. Hand forced grasping and the 'alien hand syndrome' in a patient with a frontomesial lesion: video-EEG/stereo-EEG correlation. Epilepsia 1998;39(suppl 2):64.

56. Leiguarda R, Starkstein S. Nogués M, Berthier M, Arbelaiz R. Paroxysmal alien hand syndrome. J Neurol Neurosurg Psychiatry 1998;65:366-369.

57. Andre C, Domingues R. Transient alien hand syndrome: is this a seizure or a transient ischaemic attack? Letter to Editor. J Neurol Neurosurg Psychiatry 1997;63:232-233.

58. Dolado AM, Castrillo C, Urra DG, DeSeijas EV. Alien hand sign or alien hand syndrome? J Neurol Neurosurg Psychiatry 1995;59:100-101.

59. Libet B. Neural time factors in conscious and unconscious mental functions. In: Toward a Science of Consciousness II. Hameroff SR, Kasziak AW, Scott AC, Cambridge MA. eds. The Second Tucson Discussion and Debates. MIT Press 1998. Chapter 25. 